\title{
Correction to: Is fund performance driven by flows into connected funds? spillover effects in the mutual fund industry
}

\author{
Bing Zhu $\cdot$ René-Ojas Woltering ${ }^{2}$
}

Accepted: 23 March 2021 / Published online: 13 April 2021

(c) Academy of Economics and Finance 2021

\section{Correction to: Journal of Economics and Finance (2021) https://doi.org/10.1007/s12197-021-09539-7}

In the published article "Is fund performance driven by flows into connected funds? spillover effects in the mutual fund industry" second author has incorrect affiliation. Affiliation was listed as "Ecole hôtelière de Lausanne, 1000, Lausanne 25, Lausanne, Switzerland" where it should be "Ecole hôtelière de Lausanne, HES-SO University of Applied Sciences and Arts Western Switzerland, Lausanne, Switzerland".

The original article has been corrected.

Publisher's note Springer Nature remains neutral with regard to jurisdictional claims in published maps and institutional affiliations.

The online version of the original article can be found at https://doi.org/10.1007/s12197-021-09539-7

Bing Zhu

b.zhu@tum.de

René-Ojas Woltering

Rene-Ojas.WOLTERING@ehl.ch

1 Department of Civil, Geo and Environmental Engineering, Technical University of Munich, Arcisstraße 21, 80333 Münich, Germany

2 Ecole hôtelière de Lausanne, HES-SO University of Applied Sciences and Arts Western Switzerland, Lausanne, Switzerland 